\title{
Fuzzy Multi-Criteria Evaluation of Knowledge Management Tools
}

\author{
Gülçin Büyüközkan* \\ Department of Industrial Engineering, Galatasaray University, Çırağan Caddesi No: 36 \\ Ortaköy, Istanbul, 34357, Turkey \\ E-mail: gulcin.buyukozkan@gmail.com \\ Orhan Feyzioğlu \\ Department of Industrial Engineering, Galatasaray University, Çırağan Caddesi No: 36 \\ Ortaköy, İstanbul, 34357, Turkey \\ E-mail: ofeyzioglu@gsu.edu.tr-orhanfeyzioglu@gmail.com \\ Gizem Çifçi \\ Department of Industrial Engineering, Galatasaray University, Çırağan Caddesi No: 36 \\ Ortaköy, Istanbul, 34357, Turkey \\ E-mail: gizem.cifci@gmail.com
}

Received: 25-01-2010

Accepted: 26-08-2010

\begin{abstract}
In the knowledge economy, a key source of sustainable competitive advantage relies on the way to create, share, and utilize knowledge. Knowledge Management (KM) tools assumed an important role in supporting KM activities. The objective of this paper is to aid decision makers to identify the most appropriate KM tool to improve the effectiveness of their organization. In order to rate competing systems of different vendors, we propose an enhanced multi-criteria method, namely fuzzy VIKOR, that takes advantages of fuzzy logic and group decision making to deal with the vagueness and granularity in the linguistic assessments. The method aims to isolate compromise solutions, by providing a maximum group utility and a minimum of an individual regret. A case study is also given to demonstrate the potential of the methodology.
\end{abstract}

Keywords: Multi-criteria analysis, KM tools, fuzzy VIKOR, fuzzy Delphi methodology.

\section{Introduction}

Knowledge has been accepted as the most important strategic resource for high technology firms. Since successful knowledge management (KM) can provide sustainable competitive advantage, ${ }^{1-3}$ interest from both industry and academy to KM has been growing rapidly. According to Tiwana, ${ }^{4} \mathrm{KM}$ is the ability to create and retain greater value from core business competencies. Wadhwa and Saxena $^{5}$ view KM in a simple business sense as creation, sharing, adaptation, application and advancement of knowledge in enterprises to improve their performance. The role of KM is dynamic and it needs to change with the changes in customer priorities on cost, quality, time, variety, etc. ${ }^{5}$

The aim of KM can also be cost saving, increased organizational capacity, better customer service, and reduced cycle time. ${ }^{6-8}$ To maximize competitive advantage, the concept of seamless supply chains is emerging and encouraging market place knowledge to

*Corresponding Author. Phone: +90 212227 4480; Fax: +90 2122595557. 
move through supply chains as effectively as possible with $\mathrm{KM}$ and information technology (IT) as key enablers. ${ }^{5} \mathrm{KM}$ tools are then used as enablers to supply chain management to build dynamic communities connecting the enterprise with customers and suppliers. KM tools are IT based systems developed to support and enhance the organizational processes of knowledge creation, storage/retrieval, transfer, and application. ${ }^{9}$ The KM tools can provide real-time knowledge and information on the customer spanning the customer relationship lifecycle through knowledge retention and the building of customer profiles. This allows a better understanding of customers and their needs, and therefore enables more effective and efficient customer service. $^{10} \mathrm{KM}$ tools make it possible to deliver knowledge to all departments within an organization. They also integrate various knowledge processes to solve one or more business problems as an organizational information system. They also promote and enable the knowledge process in order to improve decision-making. ${ }^{14}$ The examination of the current literature shows that only limited studies ${ }^{10-17}$ exist and this paper presents an enhanced multi-criteria method to assess such tools.

Several decision problems involving the evaluation and ranking of a finite number of alternatives depending on several and usually conflicting criteria can be modeled as a multi criteria decision making (MCDM) problem. ${ }^{18}$ As there exist several techniques to solve MCDM problems, the availability and selection of an appropriate method depend on the structure of the model and the information that can be collected. It is quite natural to expect from a method to provide more robust solutions if it can successfully process more complex data. Since the human judgment mostly contains some kind of uncertainty, it is more desirable to have a tool that is able to treat information in such a fuzzy environment. ${ }^{19}$ Recently, VIKOR method has been introduced as an applicable technique to implement within $\mathrm{MCDM} .{ }^{20}$ The method provides a maximum group utility for the majority and a minimum of an individual regret for the opponent, and it introduces a multi criteria ranking index based on the particular measure of closeness to the ideal solution. ${ }^{20}$ VIKOR focuses on ranking and selecting (from a set of alternatives) in the presence of conflicting and noncommensurable criteria ${ }^{21-23}$ (such as KM tool evaluation criteria), assuming that compromising is acceptable for conflict resolution. The decision maker wants a solution that is the closest to the ideal, and the alternatives are evaluated according to all established criteria. ${ }^{22}$ Therefore, it can effectively deal with characteristics of this problem and provide a comprehensive and systematic approach that quantitatively evaluates KM tool alternatives.

In its original setting, alternatives are evaluated with exact evaluation values in VIKOR method and this can be quite restrictive with unquantifiable criteria. This inefficiency will be more exacerbated, when linguistic terms were used for the evaluations. To treat such information in the assessment process, VIKOR method can be extended based on fuzzy logic. ${ }^{19}$ Accordingly, the ambiguities involved in the assessment data can be represented efficiently and processed to assure a more convincing and effective evaluation. In this article, the extended VIKOR method is used to evaluate KM tool alternatives.

The paper is organized as follows. Section 2 and 3 present respectively the literature related to $\mathrm{KM}$ tool evaluation and the identified KM tool evaluation criteria. Section 4 introduces the details of the proposed approach. Section 5 applies the suggested approach to rate the KM systems. Finally, last section contains some concluding remarks.

\section{Literature Review for KM Tool Evaluation}

Selection of KM tools is usually a complex task due to the fact that the related decision problem is not welldefined or structured. The presence of the multiple criteria and the involvement of the multiple decisionmakers will expand decisions from one to many several dimensions; thus, it will increase the complexity of the solution process. In line with the multi-dimensional characteristics of $\mathrm{KM}$ tool performance, MCDM modeling framework provides an effective way for the evaluation with multiple attributes. Solution techniques available within MCDM make it possible to rank different KM tools (i.e. software products) when they are compared in terms of their overall performance. It is common to apply the implications of fuzzy set theory to extend MCDM methods (e.g. analytic hierarchy process (AHP), ${ }^{24}$ analytic network process (ANP), ${ }^{25}$ technique for order performance by similarity to ideal solution (TOPSIS), ${ }^{26}$ etc.) in better capturing the decision makers' preference structure. As the several performance dimensions related to KM tools cannot be 
evaluated in an exact manner, any tool ranking technique should take into account the uncertainty in the assessments.

As it can be seen from literature survey, AHP and ANP are some widely used MCDM methods where fuzzy theory can be applied. AHP method can deal with imprecision caused by the decision maker's inability to translate his/her preferences for some alternative to another into a totally consistent preference structure. In spite of their popularity and simplicity in concept, they can only obtain relative weights for criteria and alternatives; they cannot compute gaps between the status quo and an ideal point of an alternative. On the other hand, TOPSIS is another distance based MCDM method which leans on aggregating function representing "closeness to ideal". In TOPSIS the chosen alternative should have the "shortest distance" from the ideal solution and the "farthest distance" from the "negative-ideal". The TOPSIS method introduces two reference points, but it does not consider the relative importance of the distances from these points. ${ }^{22}$ Moreover, the normalized value in the VIKOR method does not depend on the evaluation unit of criterion function, whereas the normalized values by vector normalization in the TOPSIS method may depend on the evaluation unit. Therefore, VIKOR method may provide a more effective basis for developing KM tool selection models.

Literature available on software evaluation and selection using different approaches (containing MCDM techniques) are quite numerous. Here, we preferred to focus more on KM tool selection studies. Ngai and $\mathrm{Chan}^{16}$ provided a work that aims to evaluate $\mathrm{KM}$ tools using AHP methodology. They underlined that their paper was primarily concerned with providing such a framework. In another work, Tuncer and Büyüközkan ${ }^{27}$ used a fuzzy logic approach in the evaluation process by stating that subjective considerations were relevant to the KM tool decision. More precisely, they formulated a fuzzy AHP model and applied to a real case of assisting decision-makers to evaluate a suitable $\mathrm{KM}$ tool for effective supply chain management. Mulebeke and Zheng ${ }^{28}$ proposed ANP for software selection. Chan and $\mathrm{Nevo}^{29}$ aimed to explore the roles and scope of KM systems in organizations, and proposed a study to suggest a revised approach to developing organizational KM systems by using Delphi methodology. Wang and Chang $^{30}$ presented an AHP-prediction model based on the consistent fuzzy preference relations to help the organizations become aware of the essential factors affecting the success of KM implementation. Wu and Lee $^{31}$ studied the selection of KM strategies by using ANP methodology. Afterwards, $\mathrm{Wu}^{32}$ enhanced this study and used a combined ANP and DEMATEL (decision-making trial and evaluation laboratory model) approach for choosing KM strategies. A different work with more design aspect of KM systems is due to Juang, Lin and Kao. ${ }^{33}$ In this work, the authors have proposed a genetic algorithm based optimization model to improve the design efficiency of a KM system. Recently, Razmi, Sangari and Ghodsi ${ }^{34}$ developed a framework for enterprise resource planning (ERP) readiness assessment using fuzzy ANP. Similarly, ERP software selection process is proposed by Yazgan Boran and Goztepe $^{35}$ with using artificial neural network based on ANP. As another study, $\mathrm{Wen}^{36}$ developed a model for the measurement of the effectiveness of $\mathrm{KM}$ in Taiwanese high-tech enterprises with AHP. Chang and Wang $^{37}$ used a fuzzy MCDM approach and studied the measurement of successful KM possibility. In 2010, Şen and Baraçl1 $^{38}$ studied a fuzzy quality function deployment (QFD) based methodology for acquiring enterprise software selection requirements.

\section{KM Tool Evaluation Criteria}

The first step of the proposed framework is to determine the criteria needed to assess the KM tools. The KM tool evaluation criteria have been identified after a careful study of literature, ${ }^{16,17,38-47}$ examination of commercial vendor surveys, public product briefings and demos. Then, these criteria verified with external professional experts (KM consultants and vendors themselves) to ensure all criteria were well formulated and properly understood and a generic evaluation criteria list is determined.

The size of company, internal needs and competitive pressure would also influence the adoption of KM systems. Thus, the decision makers need to analyze the KM tool selection problem and case company's requirements in order to ensure the decision-making process effectively and efficiently. Fig. 1 indicates the criteria determination process of the study. In order to fulfill the expected outcome, the following ten main evaluation criteria are identified. 


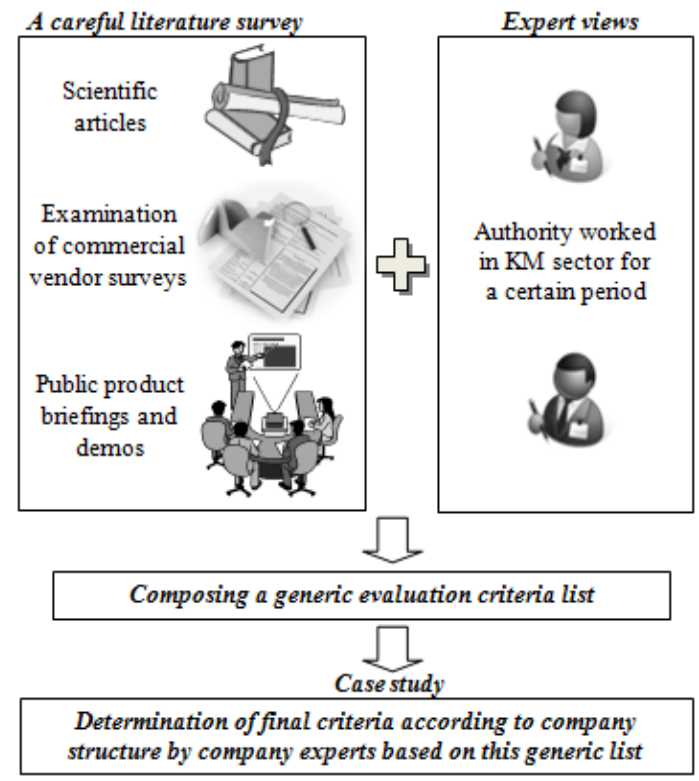

Fig. 1. Criteria determination process

- Software enhancement possibilities ${ }^{17,38,42,44,45}$ : KM systems need integration with a wide range of other daily applications. Reports of project, finance or ERP (Enterprise Resource Planning) systems or their related parameters, companies exchange servers etc. are the areas of interface. New functions can be developed from scratch too. For all such requirements, the system should provide a platform whereby additional development can easily be made.

- Compliance with company standards ${ }^{17,38,41-45}$ : Standardization of information technology applications in a global company with wide range of products in several locations is crucial. Small isolated solutions of applications result in total disorder in reporting, integration of applications and vast amount of investments can be made reinventing the wheel in each region. So software used must comply with the standards of the company.

- Document management $1^{16,17,38,44,46}$ : In knowledge organizations, large amount of knowledge is embedded within the documents. Users become productive if the documents are managed effectively. Comprehensive authorization, good search mechanism, versioning, document discussions and alerts are inevitable aspects of a document management system.
- Collaboration ${ }^{16,17,38,40-46}$ : Collaboration is the backbone of KM. It plays a substantial role in leverage of mainly tacit knowledge. Collaborative problem solving, conversation and teamwork generate a significant proportion of knowledge assets. It is also one of the three major components to e-Businesses besides information and commerce.

- Portal functions ${ }^{17,38,44,46}$ : Portals provide an easy to use entry point to knowledge domain of a global company. Hence should be easy to use, easy to personalize and if possible should facilitate single sign on functions where there are endless applications worldwide.

- Workflow facilities ${ }^{17,38,44,46}$ : Workflow facilities speed up the document flow through processes in a company. It is based upon defining the path a document travels and functions applied to this document (such as approve or reject) and people authorized to perform these functions. Workflow management is one off the main interfaces between process management and document management.

- Ease of use $e^{17,38-41,44,46}$ : Introduction of knowledge management environments can involve change management applications. Although a bottom up approach has been used for KM projects users would find a complex, hard to use system difficult to adopt. This would hinder the deployment efforts of the project team, causing unnecessary delays.

- Capital expenditure ${ }^{16,17,40,41,43}$ : Capital costs are non recurring expenditures involved in setting up the KM system product, licenses and training costs are of this definition.

- Operating expenditure $e^{16,17,39-41,43}$ : Operating expenditures are recurring costs based on day to day operations of the system.

- Vendor reputation ${ }^{16,17,38,44,47}$ : The vendor as a business partner should care about the quality of services and support given to the customer. Its expertise and experience in the area of KM gives the customer more confidence in the tool. If we consider that KM is only a new subject it is hard to find experienced employees in some regions.

\section{Proposed Analytic Approach: Group Decision Making based Fuzzy VIKOR Method}

Problems treated within MCDM framework usually involve multiple conflicting criteria. Such problems require comparisons of alternative solutions on the basis of criteria and usually include implicit or explicit tradeoffs between the criteria. ${ }^{48}$ One category of MCDM 
methods consists of the distance-based or compromise programming techniques that seek a solution that is close to an ideal solution, or like the Nash cooperative game concept, a solution that is distant as far as possible from the worst solution. ${ }^{49}$ Belonging to this compromise programming category, VIKOR method was introduced as an applicable technique to implement within MCDM. ${ }^{20,50-64}$ It is developed to focus on ranking and selecting from a set of alternatives in the presence of conflicting criteria. VIKOR method aids to determine the compromise ranking-list and the compromise solution by introducing the multi criteria ranking index based on the particular measure of "closeness" to the "ideal" solution. ${ }^{20}$ The compromise solution, whose foundation was established by $\mathrm{Yu}^{65}$ and Zeleny, ${ }^{66}$ is a feasible solution, which is the closest to the ideal, and here "compromise" means an agreement established by mutual concessions. With its ability to provide compromise solution(s), VIKOR is selected in this work as a suitable method for evaluating KM tools. We refer the readers to the work of Opricovic and Tzeng ${ }^{50}$ for the essences of VIKOR method.

VIKOR method is based on the concept of accurate measurement and crisp evaluation, i.e., the assessments of alternatives must be in exact numerical values. However, owing to the unavailability or uncertainty of information, it is very difficult to evaluate $\mathrm{KM}$ tools with certainty. Most evaluators tend to give assessments based on their knowledge, past experience and subjective judgments. As an example, "quality" is a variable that can be rated more comfortably with linguistic values rather than numerical ones, i.e., poor, fair, good, very good, etc. To deal with the vagueness of human thought, fuzzy set theory can play a significant role in this kind of decision-making environment. The approximate reasoning of fuzzy set theory can properly represent linguistic terms. ${ }^{67}$ To tackle the ambiguities involved in the process of linguistic estimations, it is better to convert these linguistic terms to fuzzy numbers. Hence, the value of a linguistic variable can be quantified and extended to mathematical operations using fuzzy set theory. ${ }^{19,68}$ There exist several computational models about computing with words in the literature. ${ }^{69-71}$

Opricovic and Tzeng ${ }^{72,73}$ have also suggested using fuzzy logic for VIKOR method. However, they simply used fuzzy values to define the attributes' ratings and their importance at the first phase of their study, and then, by applying a defuzzification technique, they applied VIKOR method with crisp data. Here, we suggest using fuzzy logic in the subsequent phases of VIKOR method without losing any important information with the mapping process at beginning. In the literature, there are limited number of studies that apply fuzzy VIKOR. Büyüközkan, Ruan and Feyzioğlu $^{74}$ have applied this approach to measure the performance of e-learning web sites, while Büyüközkan and Ruan ${ }^{75}$ employed it for evaluating the ERP software products. Recently, Chen and $\mathrm{Wang}^{76}$ optimized partners' choice in IS/IT outsourcing projects using fuzzy VIKOR while Sanayei, Mousavi and Yazdankhah $^{22}$ used fuzzy VIKOR for supplier selection.

Group decision-making is another important concern in this study. Multiple evaluators are often preferred rather than a single evaluator ${ }^{77-82}$ to avoid the bias and to minimize the partiality in the decision process. ${ }^{83}$ The presence of multiple criteria and the involvement of multiple evaluators will expand the decision space from one to many dimensions, thus the complexity of the decision process will increase.

Fig. 2 briefly illustrates the proposed methodology. Lets denote $m$ alternatives under consideration as $a_{1}, a_{2}, \ldots, a_{m}$, and $n$ evaluation criteria as $c_{1}, c_{2}, \ldots, c_{n}$. Then, the steps of our approach are as follows.

Step 1. Construct a committee of experts with $K$ members and determine the alternatives and evaluation criteria.

Step 2. Identify the evaluation base, in other words the linguistic variables for weighting criteria and the linguistic ratings for the alternatives as given in Tables 1 and 2 .

Table 1. Linguistic variables for rating criteria importance

\begin{tabular}{ccc}
\hline Variable & Symbol & Fuzzy Scale \\
\hline Very High & VH & $(0.7,1.0,1.0)$ \\
High & $\mathrm{H}$ & $(0.5,0.7,1.0)$ \\
Medium & $\mathrm{M}$ & $(0.2,0.5,0.8)$ \\
Low & $\mathrm{L}$ & $(0.0,0.3,0.5)$ \\
Very Low & VL & $(0.0,0.0,0.3)$ \\
\hline
\end{tabular}




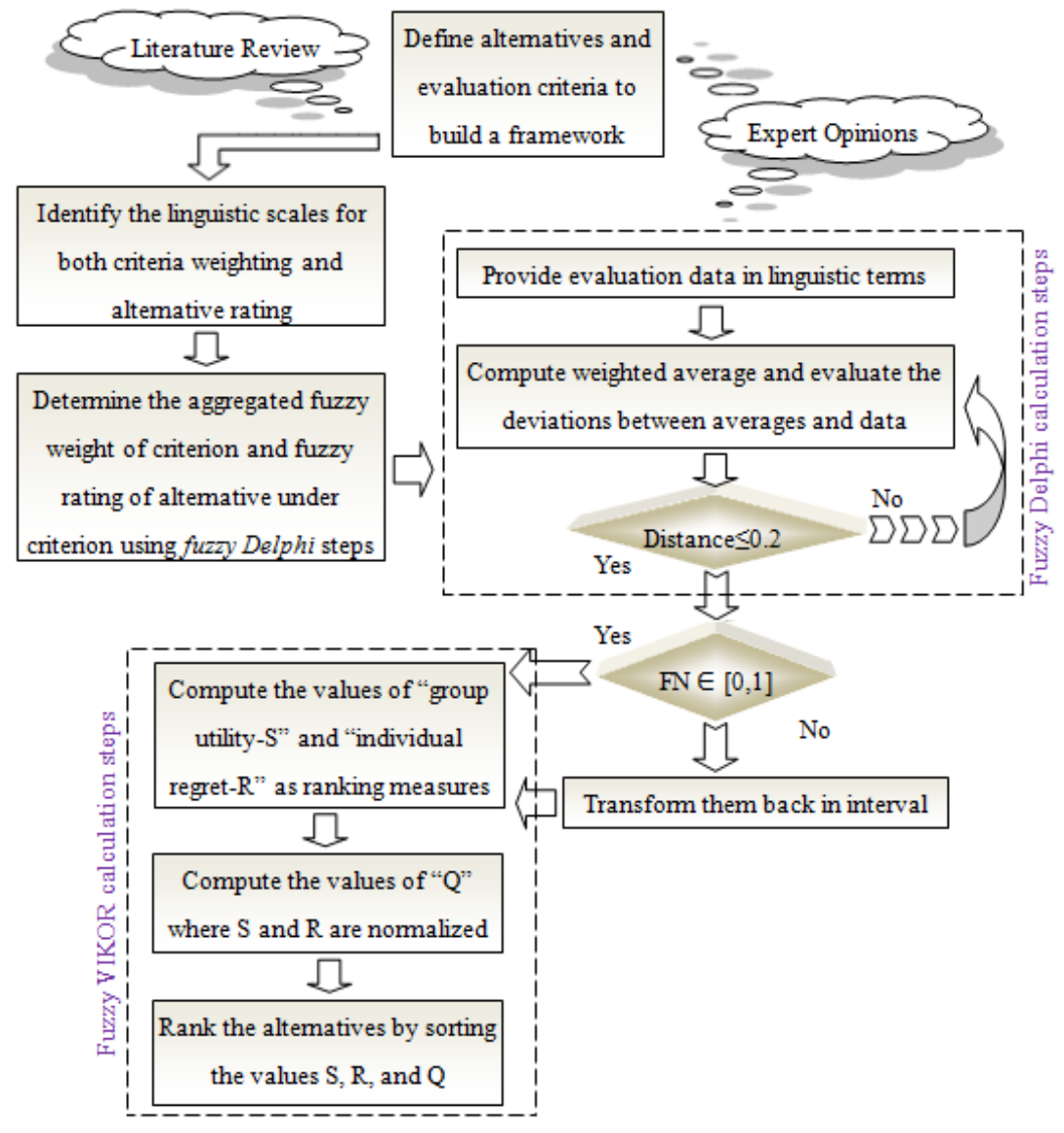

Fig. 2. Proposed methodology of the study

Table 2. Linguistic variables for rating alternatives

\begin{tabular}{ccc}
\hline Variable & Symbol & Fuzzy Scale \\
\hline Outstanding & $\mathrm{O}$ & $(0.875,1.000,1.000)$ \\
Very Good & VG & $(0.750,0.875,1.000)$ \\
Fairly Good & FG & $(0.625,0.750,0.875)$ \\
Good & $\mathrm{G}$ & $(0.500,0.625,0.750)$ \\
Moderate & $\mathrm{M}$ & $(0.375,0.500,0.625)$ \\
Poor & $\mathrm{P}$ & $(0.250,0.375,0.500)$ \\
Fairly Poor & FP & $(0.125,0.250,0.375)$ \\
Very Poor & VP & $(0.000,0.125,0.250)$ \\
Negligible & $\mathrm{N}$ & $(0.000,0.000,0.125)$ \\
\hline
\end{tabular}

Delphi-Step 1: $K$ experts are asked to provide the evaluation data in the form of linguistic variables as illustrated in Tables 1 and 2, which in turn corresponds to the fuzzy triangular numbers $\widetilde{f}_{i j}^{k}$ and $\widetilde{w}_{i}^{k}$. In this method, each expert has a weight $\lambda_{k}$ according to his/her degree of experience.

Delphi-Step 2: First, the weighted average $\tilde{f}_{i j}$ of all $\widetilde{f}_{i j}^{k}$ 's and $\widetilde{w}_{i}$ of all $\widetilde{w}_{i}^{k}$ 's are computed as follows:

$$
\begin{gathered}
\tilde{f}_{i j}=\frac{\left(\lambda_{1} \otimes \tilde{f}_{i j}^{1}\right) \oplus \ldots \oplus\left(\lambda_{k} \otimes \tilde{f}_{i j}^{k}\right)}{\lambda_{1}+\ldots+\lambda_{k}} \\
\tilde{w}_{i}=\frac{\left(\lambda_{1} \otimes \tilde{w}_{i}^{1}\right) \oplus \ldots \oplus\left(\lambda_{k} \otimes \tilde{w}_{i}^{k}\right)}{\lambda_{1}+\ldots+\lambda_{k}} .
\end{gathered}
$$

Then for each expert, the deviation between the weighted average $\widetilde{f}_{i j}$ and $\widetilde{f}_{i j}^{k}$ is computed. The same procedure is also applied for the deviation between the weighted average $\widetilde{w}_{i}$ and $\widetilde{w}_{i}^{k}$. At this point, the distance of fuzzy numbers is calculated using our proposed method in order to evaluate the deviations between the weighted averages and experts' evaluation data. 
Delphi-Step 3: A threshold value is defined so that the deviation is sent back to the expert if the distance between the weighted average and expert's evaluation data is greater than this value. If there is any distance value being greater than the threshold value then the relevant expert is notified and the process starting with the step 2 is repeated until there is no distance value exceeding the threshold value.

This process is repeated until two successive averages are reasonably close to each other. It is assumed that the distance being less than or equal to 0.2 corresponds to two reasonably close fuzzy estimates. ${ }^{84}$ We also suggest this threshold.

Step 4. If the supports of triangular fuzzy numbers expressing linguistic variables (Tables 1 and 2) do not belong to the interval $[0,1]$, then a scaling is needed to transform them back in this interval. Here, we use a linear scale transformation to have a comparable number. As an example, if we transform the rating of alternatives, we have

$$
\widetilde{r}_{i j}=\left(\frac{f_{i j}^{1}}{f_{i}^{\max }}, \frac{f_{i j}^{2}}{f_{i}^{\max }}, \frac{f_{i j}^{3}}{f_{i}^{\max }}\right),
$$

where

$\tilde{f}_{i j}=\left(f_{i j}^{1}, f_{i j}^{2}, f_{i j}^{3}\right)$,

$f_{i}^{\max }=\max _{j} f_{i j}^{3} i=1,2, \ldots, n$.

Step 5. Compute the values of $\tilde{S}_{j}$ and $\widetilde{R}_{j} j=1,2, \ldots, m$ by the relations

$$
\begin{gathered}
\widetilde{S}_{j}=\bigoplus_{i=1}^{n} \widetilde{w}_{i} d\left(\tilde{1}, \widetilde{r}_{i j}\right), \\
\widetilde{R}_{j}=\max _{i} \widetilde{w}_{i} d\left(\tilde{1}, \widetilde{r}_{i j}\right),
\end{gathered}
$$

where $\widetilde{S}_{j}$ and $\widetilde{R}_{j}$ are used for formulating the ranking measure of "group utility" and the "individual regret" respectively. Here, $d\left(\widetilde{1}, \widetilde{r}_{i j}\right)$ represents the distance of an alternative rating to the positive ideal solution $\tilde{1}=(1,1,1)$ calculated by area compensation method. This method is due to Fortemps and Roubens ${ }^{85}$ and has reasonable ordering properties ${ }^{86}$ and computational easiness (see Appendix for details). Note that the maximum among $\widetilde{w}_{i} d\left(\widetilde{1}_{\sim}, \widetilde{r}_{i j}\right)$ values is the one that is the most distant from $\tilde{1}$.
Step 6. Compute the values $\widetilde{Q}_{j} \quad j=1,2, \ldots, m$ by the relation

$$
\widetilde{Q}_{j}=v\left(\widetilde{S}_{j}^{\prime}\right) \oplus(1-v)\left(\widetilde{R}_{j}^{\prime}\right),
$$

where $\widetilde{S}_{j}^{\prime}$ and $\widetilde{R}_{j}^{\prime}$ are normalized $\widetilde{S}_{j}$ and $\widetilde{R}_{j}$ values using the linear scale transformation. Here, " $v$ " is introduced as a weight of the strategy of "the majority of criteria" as proposed in the original VIKOR method. The compromise can be selected with "voting by majority" $(v>0.5)$, with "consensus" $(v=0.5)$, or with "veto" $(v<0.5)$.

Step 7. The ranking order of alternatives is determined with the help of the area compensation $\operatorname{method}^{70}$. First, $\widetilde{S}_{j}^{\prime}, \widetilde{R}_{j}^{\prime}$ and $\widetilde{Q}_{j}$ values are defuzzified into crisp $\widetilde{S}_{j}^{\prime}, \widetilde{R}_{j}^{\prime}$ and $\widetilde{Q}_{j}$ values. Then, alternatives are ranked by sorting each $\widetilde{S}_{j}^{\prime}, \widetilde{R}_{j}^{\prime}$ and $\widetilde{Q}_{j}$ values in an increasing order as in the original VIKOR method. The result is a set of three ranking lists denoted as $\widetilde{S}_{[\cdot]}^{\prime}, \widetilde{R}_{[\bullet]}^{\prime}$ and $\widetilde{Q}_{[\bullet]}$. The alternative $j_{1}$ corresponding to $Q_{[1]}$ (the smallest among $Q_{i}$ values) is proposed as a compromise solution if

C1. The alternative $j_{1}$ has an acceptable advantage, in other words $Q_{[2]}-Q_{[1]} \geq D Q$ where $D Q=1 /(m-1)$ and $m$ is the number of the alternatives.

C2. The alternative $j_{1}$ is stable within the decision making process, in other words it is also the best ranked in $\widetilde{S}_{[\bullet]}^{\prime}$ or $\widetilde{R}_{[\bullet]}^{\prime}$.

If one of the above conditions is not satisfied, then a set of compromise solutions is proposed, which consists of:

- The alternatives $j_{1}$ and $j_{2}$ where $Q_{j 2}=Q_{[2]}$ if only the condition $\mathbf{C 2}$ is not satisfied, or

- The alternatives $j_{1}, j_{2}, \ldots, j_{k}$ if the condition $\mathbf{C 1}$ is not satisfied; and $j_{k}$ is determined by the relation $Q_{[k]}-Q_{[1]}<D Q$ for maximum k where $Q_{j k}=Q_{[k]}$ (the positions of these alternatives are in closeness).

\section{Application of the Proposed Approach}

The proposed evaluation framework is applied to a real case with the purpose of assisting decision-makers in the local branch (briefly called XYZ) of an internationally recognized corporation. First of all, the central firm is truly global in the sense that to share knowledge, employees must use very diverse means in addition to traditional face to face communications. The aspects of KM that involve technology enabled repositories and sharing networks were well suited to the company to overcome the geographical barriers. The information technology driven nature of the company's 
business also provides a strong motivation to manage knowledge effectively. In summary, it was necessary to establish a KM system for the XYZ Company to enable employees to access all the dimensions of the company knowledge easily while contributing to the whole KM process by the necessary inputs from the experiences gained.

Step 1. A group of five domain experts conducted the evaluation process. As the participation and support of top managers significantly influences the success of KM tool adoption, one member of the committee was a top manager. Two other members of the committee were from the information technology department, each having considerable experience in corporate projects involving change management. The last two members were senior representatives and potential users of the KM tools. All experts were treated equally. Then, the experts were required to evaluate three main KM tools as alternatives: A tool introduced by Opentext, namely Livelink (alternative A), Microsoft product Sharepoint Portal (alternative B) and Hyperwave (alternative C).

Step 2. As mentioned previously, the experts expressed their preference for criteria weights and alternatives linguistically (see Table 1 and Table 2). Three determined alternatives are to be evaluated versus ten evaluation criteria. The evaluations of experts are given in Tables 3-6.

Table 3. The linguistic evaluation of criteria importance

\begin{tabular}{lccccc}
\hline & \multicolumn{5}{c}{ Evaluators } \\
& 1 & 2 & 3 & 4 & 5 \\
\hline Software enhancement & VL & L & L & VL & L \\
Compliance & H & VH & H & VH & VH \\
Document management & H & H & M & H & H \\
Collaboration facilities & M & L & M & M & H \\
Portal functions & M & M & M & H & M \\
Workflow facilities & L & VL & VL & VL & VL \\
Ease of use & H & M & M & M & H \\
Capital expenditure & L & L & H & M & L \\
Operating expenditure & M & H & M & M & H \\
Vendor reputation & VH & H & VH & VH & H \\
\hline
\end{tabular}

Table 4. The linguistic evaluation of alternative A

\begin{tabular}{lccccc}
\hline & \multicolumn{5}{c}{ Evaluators } \\
& 1 & 2 & 3 & 4 & 5 \\
\hline Software enhancement & G & M & M & M & G \\
Compliance & O & VG & O & G & VG \\
Document management & FG & G & M & M & G \\
Collaboration facilities & FG & VG & G & G & M \\
Portal functions & FP & P & P & VP & FP
\end{tabular}

\begin{tabular}{lccccc} 
Workflow facilities & M & G & M & FP & P \\
Ease of use & P & FP & P & P & FP \\
Capital expenditure & VG & VG & G & VG & G \\
Operating expenditure & G & G & FG & M & M \\
Vendor reputation & M & G & M & G & G \\
\hline
\end{tabular}

Table 5. The linguistic evaluation of alternative B

\begin{tabular}{lccccc}
\hline & \multicolumn{5}{c}{ Evaluators } \\
& 1 & 2 & 3 & 4 & 5 \\
\hline Software enhancement & P & FP & P & VP & FP \\
Compliance & VP & FP & P & VP & VP \\
Document management & FP & VP & FP & VP & VP \\
Collaboration facilities & FP & VP & FP & FP & VP \\
Portal functions & M & G & FG & M & G \\
Workflow facilities & M & G & P & M & P \\
Ease of use & FG & G & G & VG & M \\
Capital expenditure & VP & FP & P & VP & P \\
Operating expenditure & FP & FP & VP & P & P \\
Vendor reputation & G & VG & FG & M & G \\
\hline
\end{tabular}

Table 6. The linguistic evaluation of alternative $\mathrm{C}$

\begin{tabular}{lccccc}
\hline & \multicolumn{5}{c}{ Evaluators } \\
& 1 & 2 & 3 & 4 & 5 \\
\hline Software enhancement & M & M & FG & G & G \\
Compliance & FP & VP & VP & P & VP \\
Document management & G & FG & G & M & M \\
Collaboration facilities & G & G & M & G & M \\
Portal functions & G & G & P & M & G \\
Workflow facilities & FG & G & M & M & G \\
Ease of use & M & G & P & FP & P \\
Capital expenditure & P & FP & P & P & VP \\
Operating expenditure & G & M & G & M & M \\
Vendor reputation & FP & P & P & VP & VP \\
\hline
\end{tabular}

Step 3. The fuzzy decision matrix is constructed with the linguistic evaluations of experts. Then, the aggregated fuzzy weights of criteria and the aggregated fuzzy ratings of alternatives are calculated through the weighted fuzzy Delphi methodology. The results are shown in Table 7.

Step 4. The fuzzy decision matrix was normalized in this step. The normalized matrix is the same as one given in Table 7 because of the scale selected for linguistic variables.

Steps 5 and 6. $S, R$ and $Q$ values were computed by selecting $v=0.8$ and are shown in Table 8 .

Step 7. Table 9 gives the defuzzification scores of alternatives computed with the area compensation method and the corresponding rankings. Given these results, we observe that condition $\mathrm{C} 2$ is satisfied whereas $\mathrm{C} 1$ is not. However, in this special case, the number of alternatives are not enough numerous, and 
condition $\mathrm{C} 1$ is difficult to satisfy. Then, we selected alternative A (Opentext Livelink) as the most appropriate $\mathrm{KM}$ tool. Meanwhile, alternatives B (Sharepoint Portal) and C (Hyperwave) are almost equally valuable. extends VIKOR method that helps DMs to achieve an acceptable compromise of the maximum "group utility" of the "majority" and the minimum of the individual regret of the "opponent". In the extended method, the importance weights of criteria and the ratings of alternatives are assessed in linguistic terms by triangular

Table 7. Aggregate fuzzy criteria weights and alternatives ratings

\begin{tabular}{lcccc}
\hline & Criteria & & Ratings of & \\
& Weights & Alternative A & Alternative B & Alternative C \\
\hline Software enhancement & $(0.0,0.2,0.4)$ & $(0.43,0.55,0.68)$ & $(0.15,0.28,0.40)$ & $(0.48,0.60,0.73)$ \\
Compliance & $(0.6,0.9,1.0)$ & $(0.75,0.88,0.95)$ & $(0.08,0.20,0.33)$ & $(0.08,0.20,0.33)$ \\
Document management & $(0.4,0.7,1.0)$ & $(0.48,0.60,0.73)$ & $(0.05,0.18,0.30)$ & $(0.48,0.60,0.73)$ \\
Collaboration facilities & $(0.2,0.5,0.8)$ & $(0.55,0.68,0.80)$ & $(0.08,0.20,0.33)$ & $(0.45,0.58,0.70)$ \\
Portal functions & $(0.3,0.5,0.8)$ & $(0.15,0.28,0.40)$ & $(0.48,0.60,0.73)$ & $(0.43,0.55,0.68)$ \\
Workflow facilities & $(0.0,0.1,0.3)$ & $(0.33,0.45,0.58)$ & $(0.35,0.48,0.60)$ & $(0.48,0.60,0.73)$ \\
Ease of use & $(0.3,0.6,0.9)$ & $(0.20,0.33,0.45)$ & $(0.55,0.68,0.80)$ & $(0.30,0.43,0.55)$ \\
Capital expenditure & $(0.1,0.4,0.7)$ & $(0.65,0.78,0.90)$ & $(0.13,0.25,0.38)$ & $(0.18,0.30,0.43)$ \\
Operating expenditure & $(0.3,0.6,0.9)$ & $(0.48,0.60,0.73)$ & $(0.15,0.28,0.40)$ & $(0.43,0.55,0.68)$ \\
Vendor reputation & $(0.6,0.9,1.0)$ & $(0.45,0.58,0.70)$ & $(0.55,0.68,0.80)$ & $(0.13,0.25,0.38)$ \\
\hline
\end{tabular}

Table 8. $S_{j}, R_{j}$ and $Q_{j}$ values for $v=0.8$

\begin{tabular}{cccc}
\hline & Alternative A & Alternative B & Alternative C \\
\hline$S_{j}$ & $(1.16,2.15,3.28)$ & $(1.78,3.24,4.78)$ & $(1.77,3.07,4.31)$ \\
$R_{j}$ & $(0.26,0.37,0.43)$ & $(0.50,0.70,0.80)$ & $(0.50,0.70,0.80)$ \\
$S_{j}^{\prime}$ & $(0.24,0.45,0.69)$ & $(0.37,0.68,1.00)$ & $(0.37,0.64,0.90)$ \\
$R_{j}^{\prime}$ & $(0.26,0.37,0.43)$ & $(0.50,0.70,0.80)$ & $(0.50,0.70,0.80)$ \\
$Q_{j}$ & $(0.25,0.43,0.63)$ & $(0.40,0.68,0.96)$ & $(0.40,0.65,0.88)$ \\
\hline
\end{tabular}

Table 9. Ranking of alternatives

\begin{tabular}{ccccccc}
\hline & \multicolumn{2}{c}{$S$} & \multicolumn{2}{c}{$R$} & \multicolumn{2}{c}{$Q$} \\
& Dist. & Rank & Dist. & Rank & Dist. & Rank \\
\hline Alternative A & 0.46 & $\mathbf{1}$ & 0.36 & $\mathbf{1}$ & 0.44 & $\mathbf{1}$ \\
Alternative B & 0.68 & 3 & 0.68 & 2 & 0.68 & 3 \\
Alternative C & 0.64 & 2 & 0.68 & 3 & 0.65 & 2 \\
\hline
\end{tabular}

\section{Concluding Remarks}

For reacting to an increasingly rival business environment, many companies emphasize the importance of KM systems. However, here raises a critical issue of how companies can better evaluate and select a favorable tool to a successful KM support. This study proposed a fuzzy MCDM framework to effectively solve KM tool evaluation problem under a fuzzy environment. Such evaluation is an important decision for any enterprise to achieve competitive advantage. Based on the literature survey and with the validation of industrial experts, we first defined possible KM tool evaluation criteria and formulated a fuzzy multi criteria evaluation model. The approach basically fuzzy numbers. By using the suggested approach, the ambiguities involved in the assessment data could be effectively represented and processed to assure a more convincing and effective evaluation process.

Although the extended method presented in this paper is applied to the KM tool evaluation problem, it can also be used to help DMs to identify acceptable compromises in many software evaluation problems. In the future, we aim to consider evaluation criteria dependency which is generally less involved issue in MCDM methods. More precisely, we want to apply a decision framework based on the Choquet integral aggregation, ${ }^{87-89}$ that takes into account interaction among evaluation criteria. We believe that it will be good practice to exploit this method for the KM tool evaluation problem and to compare the results. Although not encountered during this study, there can be also some assessments that could not be collected or expressed in different scales during the evaluation process. This case is considered as a future research direction where evaluation practices containing incomplete preference relations ${ }^{90}$ or different scales $^{91}$ can be applied.

\section{Acknowledgements}

The authors would like to express their gratitude to the industrial experts for their support in evaluation of the framework. The authors acknowledge also the financial support of the Galatasaray University Research Fund. 


\section{References}

1. P. F. Drucker, Management Challenges for the 21st Century (Harper Business, 1999).

2. L. Edvinsson, Corporate Longitude (Prentice Hall, London, 2002).

3. I. Nonaka and H. Takeuchi, The Knowledge Creating Company (Oxford University Press, New York, 1995).

4. A. Tiwana, The Knowledge Management Toolkit (Prentice Hall, India, 2000).

5. S. Wadhwa and A. Saxena, Decision knowledge sharing: flexible supply chains in KM context, Production Planning \& Control 18(5) (2007) 436-452.

6. PriceWaterhouseCoopers, KM business value: lessons learned from early adopters, Global Enterprise Advisor 10 (1999) 7-8.

7. PriceWaterhouseCoopers, E-commerce professional services firms: clarifying choices, Global Enterprise Advisor 10 (1999) 9-11.

8. M. Du Plessis, Drivers of knowledge management in the corporate environment, International Journal of Information Management 25 (2004) 193-202.

9. M. Alavi and D. E. Leidner, Review: Knowledge management and knowledge management: Conceptual foundations and research issues, MIS Quartely 25 (2001), 107-136.

10. M. Du Plessis, Drivers of knowledge management in the corporate environment, International Journal of Information Management 25 (2005) 193-202.

11. C. J. Neels-Kruger and R. D. Johnson, Information management as an enabler of knowledge management maturity: A South African perspective, International Journal of Information Management 30(1) (2010) 57-67.

12. Y. A. Pollalis and N. K. Dimitriou, Knowledge management in virtual enterprises: A systemic multimethodology towards the strategic use of information, International Journal of Information Management 28 (2008) 305-321.

13. J. Yang, Antecedents and consequences of knowledge management strategy: the case of Chinese high technology firms, Production Planning \& Control 19(1) (2008) 67-77.

14. P. Tyndale, A taxonomy of knowledge management software tools: origins and applications, Evaluation and Program Planning 25 (2002) 183-190.

15. R. Ruggles, Knowledge management tools (Butterworth-Heinemann, Oxford, 1997.)

16. E. W. T. Ngai and E. W. C. Chan, Evaluation of knowledge management tools using AHP, Expert Systems with Applications 29 (2005) 889-899.

17. Y.E. Albayrak, A Fuzzy Linear Programming Model for Multiattribute Group Decision Making: An Application to Knowledge Management, Journal of Multiple-Valued Logic and Soft Computing 14(3-5) (2008) 339-354.
18. J. -C. Pomerol and S. Barba-Romero, Multicriterion Decision in Management: Principles and Practice (Kluwer Academic, Boston, 2000).

19. L. A. Zadeh, Fuzzy Sets, Information \& Control 8 (1965) 338-353.

20. S. Opricovic, Multicriteria optimization of civil engineering systems (Faculty of Civil Engineering, Belgrade, 1998).

21. S. Opricovic and G. -H. Tzeng, Extended VIKOR method in comparison with outranking methods, European Journal of Operational Research 178 (2007) 514-529.

22. A. Sanayei, S. F. Mousavi and A. Yazdankhah, Group decision making process for supplier selection with VIKOR under fuzzy environment, Expert Systems with Applications 37(1) 2010 2-30.

23. W. -H. Tsai, W. -C. Chou and C.-W. Lai, An effective evaluation model and improvement analysis for national park websites: A case study of Taiwan, Tourism Management 31(6) (2010) 936-952.

24. T. L. Saaty, The Analytic Hierarchy Process (McGraw Hill Company, 1980).

25. T. L. Saaty, The Analytic Network Process (Pittsburgh, PA: RWS Publications. 1996).

26. C. L. Hwang and K. Yoon, Multiple Attribute Decision Making Methods and Applications (SpringerVerlag, New York, 1981).

27. L. Tuncer, and G. Büyüközkan, Evaluation of Knowledge Management Tools for Effective Supply Value Chain. Proceedings of the 3rd International Logistics and Supply Chain Congress, Istanbul, Turkey, 23-24 November, (2005). 414-422.

28. J. A. W. Mulebeke and L. Zheng, Analytical network process for software selection in product development: A case study, Journal of Engineering and Technology Management 23 (2006) 337-352.

29. D. Nevo and Y. E. Chan, A Delphi study of knowledge management systems: Scope and requirements, Information \& Management 44(6) (2007) 583-597.

30. T. -C. Wang and T. -H. Chang, Forecasting the probability of successful knowledge management by consistent fuzzy preference relations, Expert Systems with Applications 32(3) (2007) 801-813.

31. W. -W. Wu and Y. -T. Lee, Selecting knowledge management strategies by using the analytic network process, Expert Systems with Applications 32 (2007) 841-847.

32. W. -W. Wu, Choosing knowledge management strategies by using a combined ANP and DEMATEL approach, Expert Systems with Applications 35 (2008) 828-835.

33. Y. -S. Juang, S. -S. Lin and H. -P. Kao, A knowledge management system for series-parallel availability optimization and design, Expert Systems with Applications 34(1) (2008) 181-193. 
34. J. Razmi, M. S. Sangari and R. Ghodsi, Developing a practical framework for ERP readiness assessment using fuzzy analytic network process, Advances in Engineering Software 40 (2009) 1168-1178.

35. H. R. Yazgan, S. Boran and K. Goztepe, An ERP software selection process with using artificial neural network based on analytic network process approach, Expert Systems with Applications 36 (2009) 9214-9222.

36. Y. -F. Wen, An effectiveness measurement model for knowledge management, Knowledge-Based Systems 22(5) (2009) 363-367.

37. T.-H. Chang and T. -C. Wang, Using the fuzzy multi-criteria decision making approach for measuring the possibility of successful knowledge management, Information Sciences 179(4) (2009) 355-370.

38. C. G. Şen and Hayri Baraçl, Fuzzy quality function deployment based methodology for acquiring enterprise software selection requirements, Expert Systems with Applications 37(4) (2010) 3415-3426.

39. V. S. Lai, R. P. Trueblood and B. K. Wong, Software selection: a case study of the application of the analytical hierarchical process to the selection of a multimedia authoring system, Information \& Management 36 (1999) 221-232.

40. J. Sarkis and R. P. Sundarraj, Factors for strategic evaluation of enterprise information technologies, International Journal of Physical Distribution and Logistics Management 30 (2000) 196-220.

41. M. C. Y. Tam and V. M. R. Tummala, An application of the AHP in vendor selection of a telecommunications system, Omega 29 (2001) 171-182.

42. A. Tiwana and B. Ramesh, Integrating knowledge on the web, IEEE Internet Computing 5 (2001) 2-9.

43. J. Sarkis and S. Talluri, Evaluating and selecting ecommerce software and communication systems for a supply chain, European Journal of Operational Research 159 (2004) 318-329.

44. C. G. Şen, H. Baraçli, S. Şen and H. Başligil, An integrated decision support system dealing with qualitative and quantitative objectives for enterprise software selection, Expert Systems with Applications $\mathbf{3 6}$ (2009) 5272-5283

45. ISO/IEC Standards 9126, International Standards Organisation, Information technology - software product evaluation - quality characteristics and guidelines for their use, (1991)

46. X. B. Illa, X. Franch and J. A. Pastor, Formalising ERP selection criteria, in Proc. 10th international workshop on software specification and design, (California, San Diego, Shelter Island, 2000), 115-123.

47. L. Kunda and D. Brooks, Applying social-technical approach for COTS selection, in Proc. 4th UKAIS conference: Information systems - The next generation, (University of New York, 1999), 552-565.

48. S. Zanakis, A. Solomon, N. Wishart and S. Dubish, Multi-attribute decision making: A simulation comparison of select methods, European Journal of Operations Research 107 (1998) 507-529.

49. J. Ganoulis, Evaluating alternative strategies for wastewater recycling and reuse in the Mediterranean area, Water Science and technology: Water Supply 3 (2003) 11-19.

50. S. Opricovic and G.H. Tzeng, Compromise solution by MCDM methods: a comparative analysis of VIKOR and TOPSIS, European Journal of Operational Research 156 (2004) 445-455.

51. G. H. Tzeng, C. W. Lin, and S. Opricovic, Multicriteria analysis of alternative-fuel buses for public transportation, Energy Policy 33 (2005) 1373-1383.

52. M. -T. Chu, J. Shyu, G. -H. Tzeng and R. Khosla, Comparison among three analytical methods for knowledge communities group-decision analysis, Expert Systems with Applications 33 (2007) 1011-1024.

53. C. -L. Chang and C. -H. Hsu, Multi-criteria analysis via the VIKOR method for prioritizing land-use restraint strategies in the Tseng-Wen reservoir watershed, Journal of Environmental Management 90 (2009) 3226-3230.

54. J. J. H. Liou andY. -T. Chuang, Developing a hybrid multi-criteria model for selection of outsourcing providers, Expert Systems with Applications 37 (2010) $3755-3761$.

55. H. - Y. Wu, J. - K. Chen and I-S. Chen, Innovation capital indicator assessment of Taiwanese Universities:A hybrid fuzzy model application, Expert Systems with Applications 37 (2010) 1635-1642.

56. M. K. Sayadi, M. Heydari and K. Shahanaghi, Extension of VIKOR method for decision making problem with interval numbers, Applied Mathematical Modelling 33(5) 2009 2257-2262.

57. T. Kaya and C. Kahraman, Multicriteria renewable energy planning using an integrated fuzzy VIKOR \& AHP methodology: The case of Istanbul, Energy 35(6) (2010) 2517-2527.

58. J. J. H. Liou and Y. -T. Chuang, Developing a hybrid multi-criteria model for selection of outsourcing providers, Expert Systems with Applications 37(5) (2010) 3755-3761.

59. P. Chatterjee, V. M. Athawale and S. Chakraborty, Selection of industrial robots using compromise ranking and outranking methods, Robotics and ComputerIntegrated Manufacturing 26(5) (2010) 483-489.

60. H. -Y. Wu, J. -K. Chen and I-S. Chen, Innovation capital indicator assessment of Taiwanese Universities: A hybrid fuzzy model application, Expert Systems with Applications 37(2) (2010) 1635-1642.

61. J. J. H. Liou, C. -Y. Tsai, R. -H. Lin and G. -H. Tzeng, A modified VIKOR multiple-criteria decision method for improving domestic airlines service quality, Journal of Air Transport Management (2010) in press.

62. W. -R. J. Ho, C. -L. Tsai, G. -H. Tzeng, S.-K. Fang, Combined DEMATEL technique with a novel MCDM model for exploring portfolio selection based on CAPM, Expert Systems with Applications (2010) in press. 
63. H. -Y. Wu, Y.-K. Lin and C. -H. Chang, Performance Evaluation of Extension Education Centers in Universities Based on the Balanced Scorecard, Evaluation and Program Planning (2010) in press.

64. J .-K. Chen and I-S. Chen, Aviatic Innovation System Construction using a Hybrid Fuzzy MCDM Model, Expert Systems with Applications 37(12) (2010) 8387-8394.

65. P. L. Yu, A class of solutions for group decision problems, Management Science 19 (1973) 936-946.

66. M. Zeleny, Multiple Criteria Decision Making (McGraw-Hill, New York, 1982).

67. L. A. Zadeh, The concept of a linguistic variable and its applications to approximate reasoning, Part I, Information Sciences 8 (1975) 199-249, Part II, 8, 301357; Part III, 9, 43-80.

68. A. Kaufmann and M. M. Gupta, Introduction to fuzzy arithmetic theory and applications (Van Nostrand Reinhold, New York, 1991).

69. R. Degani and G. Bortolan, The problem of linguistic approximation in clinical decision making, International Journal of Approximate Reasoning $\mathbf{2}$ (1988) 143-162.

70. M. Delgado, J. L. Verdegay and M. A. Vila, On aggregation operations of linguistic labels, International Journal of Intelligent Systems 8 (1993) 351-370.

71. F. Herrera, L. Martinez, A 2-tuple fuzzy linguistic representation model for computing with words, IEEE Transactions on Fuzzy Systems 8 (2000) 746-752.

72. S. Opricovic and G. H. Tzeng, Fuzzy Multicriteria Model for Postearthquake Land-Use Planning, Natural Hazards Review 4 (2003) 59-64.

73. S. Opricovic and G. H. Tzeng, Defuzzification within a multicriteria decision model, International Journal of Uncertainty, Fuzziness and Knowledge Based Systems 11 (2003) 635-652.

74. G. Büyüközkan, D. Ruan and O. Feyzioğlu, Evaluating e-learning Web site quality in a fuzzy environment, International Journal of Intelligent Systems 22 (2007) 567-586.

75. G. Büyüközkan and D. Ruan, Evaluation of software development projects using a fuzzy multi-criteria decision approach, Mathematics and Computers in Simulation 77(5-6) 2008 464-475.

76. Y. L. Chen, T. -C. Wang, Optimizing partners' choice in IS/IT outsourcing projects: The strategic decision of fuzzy VIKOR, International Journal of Production Economics 120(1) 2009 233-242.

77. F. Chiclana, F. Herrera, E. Herrera-Viedma, Integrating three representation models in fuzzy multipurpose decision making based on fuzzy preference relations, Fuzzy Sets and Systems 97 (1998) 33-48.

78. H. Wang, G. Wei, X. Zhao and R. Lin, Models for multiple attribute group decision making with 2-tuple linguistic assessment information, International Journal of Computational Intelligence Systems 3(3) (2010) 315324.
79. G. Wei, X. Zhao and R. Lin, Some induced aggregating operators with fuzzy number intuitionistic fuzzy information and their applications to group decision making, International Journal of Computational Intelligence Systems 3(1) (2010) 84-95.

80. J. Lu, G. Zhang and F. Wu, Team situation awareness using web-based fuzzy group decision support systems, International Journal of Computational Intelligence Systems 1(1) (2008) 50-59.

81. X. Li, D. Ruan, J. Liu and Y. Xu, A linguisticvalued weighted aggregation operator to multiple attribute group decision making with quantative and qualitative information, International Journal of Computational Intelligence Systems 1(3) (2008) 274 284.

82. F. Herrera, E. Herrera-Viedma and F. Chiclana, Multiperson decision-making based on multiplicative preference relations, European Journal of Operational Research 129 (2001) 372-385.

83. J. W. Lee and S. H. Kim, Using analytic network process and goal programming for interdependent information system project selection, Computers \& Operations Research 27 (2000) 367-382.

84. C. H. Cheng and Y. Lin, Evaluating the best main battle tank using fuzzy decision theory with linguistic criteria evaluation, European Journal of Operational Research 142 (2002) 174-186.

85. P. Fortemps and M. Roubens, Ranking and defuzzification methods based on area compensation, Fuzzy Sets and Systems 82 (1996) 319-330.

86. X. Wang and E. E. Kerre, Reasonable properties for the ordering of fuzzy quantities (I), Fuzzy Sets and Systems 118 (2001) 375-385.

87. M Grabisch, The application of fuzzy integrals in multi-criteria decision-making, European Journal of Operational Research 89 (1996) 445-456.

88. J. -L. Marichal and M. Roubens, Determination of weights of interacting criteria from a reference set, European Journal of Operational Research 124 (2000) 641-650.

89. T. Gürbüz, Multiple criteria human performance evaluation using choquet integral, International Journal of Computational Intelligence Systems 3(3) (2010) 290300.

90. E. Herrera-Viedma, F. Chiclana, F. Herrera and S. Alonso, Group Decision-Making Model with Incomplete Fuzzy Preference Relations Based on Additive Consistency, IEEE Transactions on Systems, Man, And Cybernetics-Part B: Cybernetics 37 (2007) 176-189.

91. F. Herrera, E.Herrera-Viedma and L. Martínez, A Fuzzy Linguistic Methodology to Deal With Unbalanced Linguistic Term Sets, IEEE Transactions on Fuzzy Systems 16 (2008) 354-370. 